Supporting Information

\title{
Molecular Insights into the Effect of Temperature and Functional Groups on the Nonwetting, Prewetting, Partial Wetting, and Complete Wetting Transitions of Ethanol on Graphite
}

\author{
by \\ Waralee Dilokekunakul $^{\mathrm{a}}$, Somboon Chaemchuen ${ }^{\mathrm{b}}$, Nikom Klomkliang ${ }^{\mathrm{a}, *}$

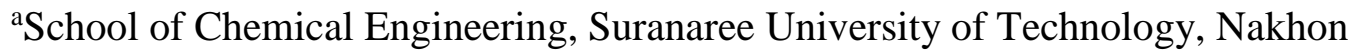 \\ Ratchasima 30000, Thailand \\ ${ }^{b}$ Laboratory of Organometallics, Catalysis and Ordered Materials, State Key \\ Laboratory of Advanced Technology for Materials Synthesis and Processing, Wuhan University \\ of Technology, Wuhan, 430070, PR China
}

*Corresponding authors: Email: nikom.klo@sut.ac.th

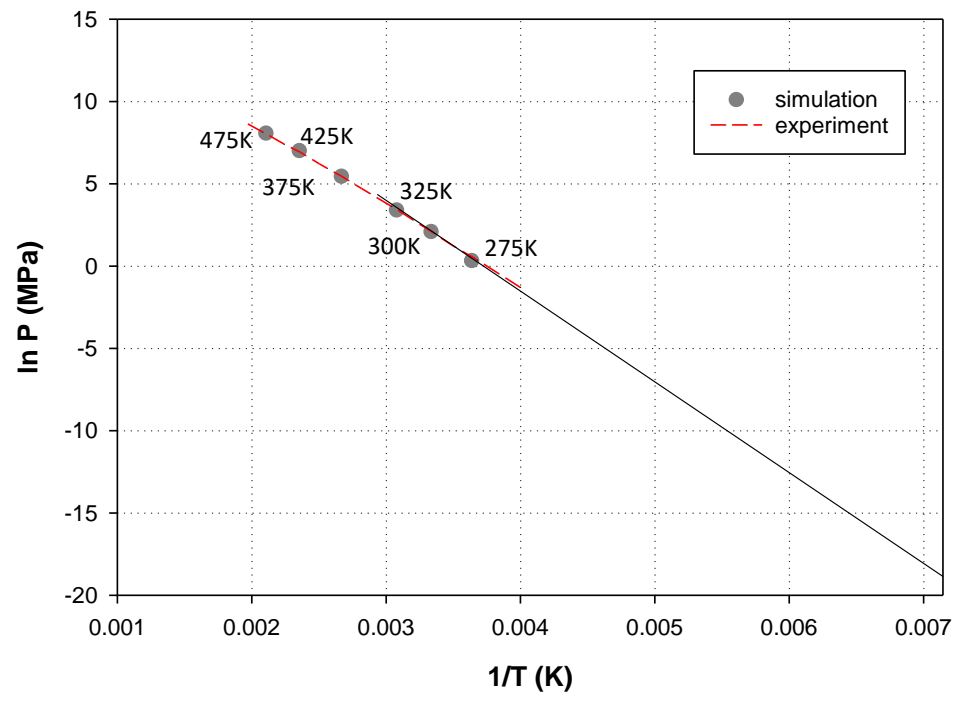

Figure S1. Extrapolation of saturation vapor pressure used in this study (120-425K) from numerical results of Gibbs-ensemble simulations using TraPPE-UA force field and experiments. ${ }^{1}$ 


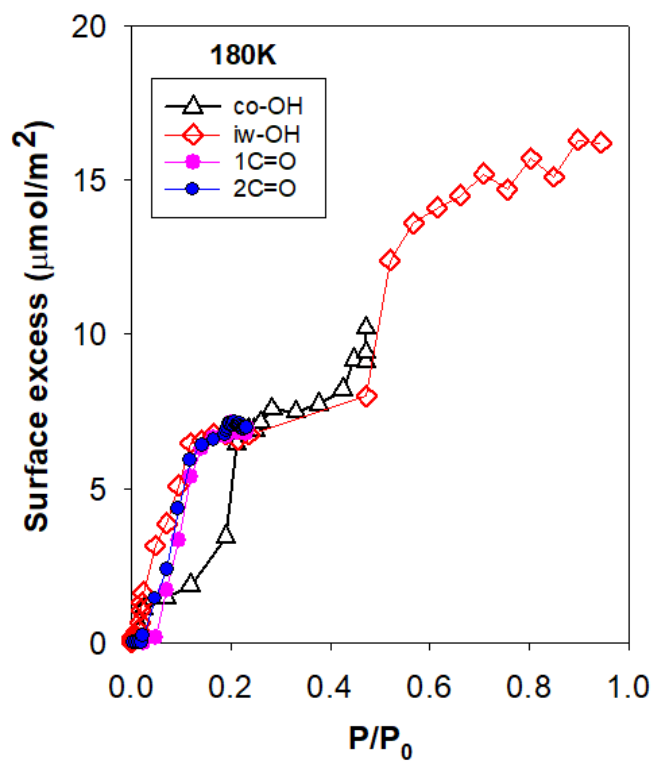

Figure S2. The comparison of ethanol adsorption on different functional group concentrations, types, and configurations. Distance between $\mathrm{C}$ atoms of functional groups is $0.5 \mathrm{~nm}$ for all models. $1 \mathrm{C}=\mathrm{O}$ refers to one $\mathrm{C}=\mathrm{O}$ group and $2 \mathrm{C}=\mathrm{O}$ refers to two $\mathrm{C}=\mathrm{O}$ groups.

We have demonstrated the effect of functional group concentration, type, and configuration as shown in Figure S2. The effect of functional group concentration can be seen during low loadings, model with higher concentration of functional group obtains higher adsorbed amount. However, all isotherms at $180 \mathrm{~K}$ follow similar pattern when the pressure increases. Likewise, in the cases of different configurations of co-OH (two $\mathrm{OH}$ groups pointing their $\mathrm{H}$ atom to the same direction) and iw-OH (two $\mathrm{OH}$ groups pointing $\mathrm{H}$ atom toward each other), and different types (iw-OH vs. $2 \mathrm{C}=\mathrm{O}$ ), although there is some difference at low loadings, all significant steps are the same. All isotherms indicate partial wetting transition at this temperature. 


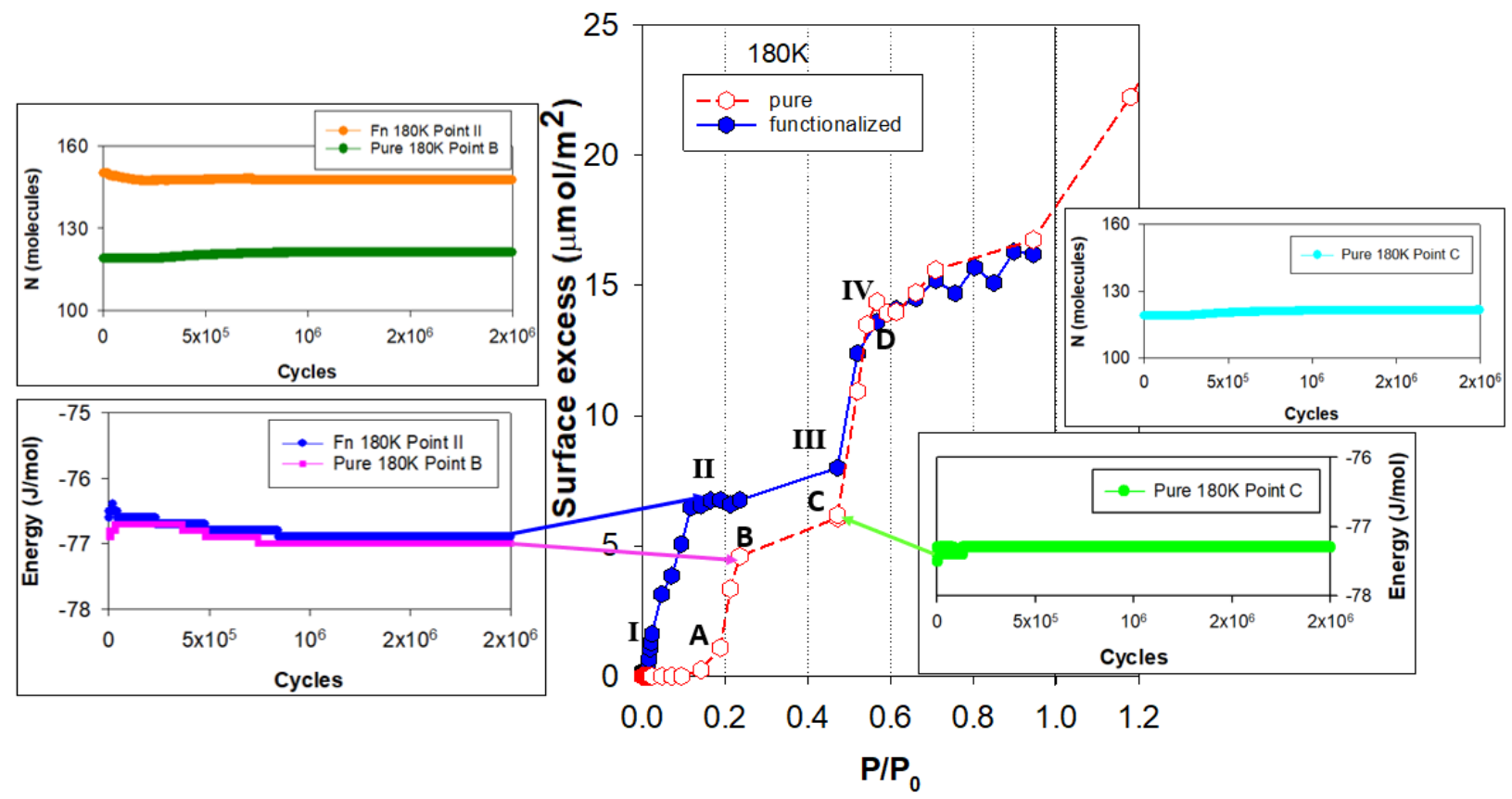

Figure S3. The control charts of energy and number of molecules during equilibrium step.

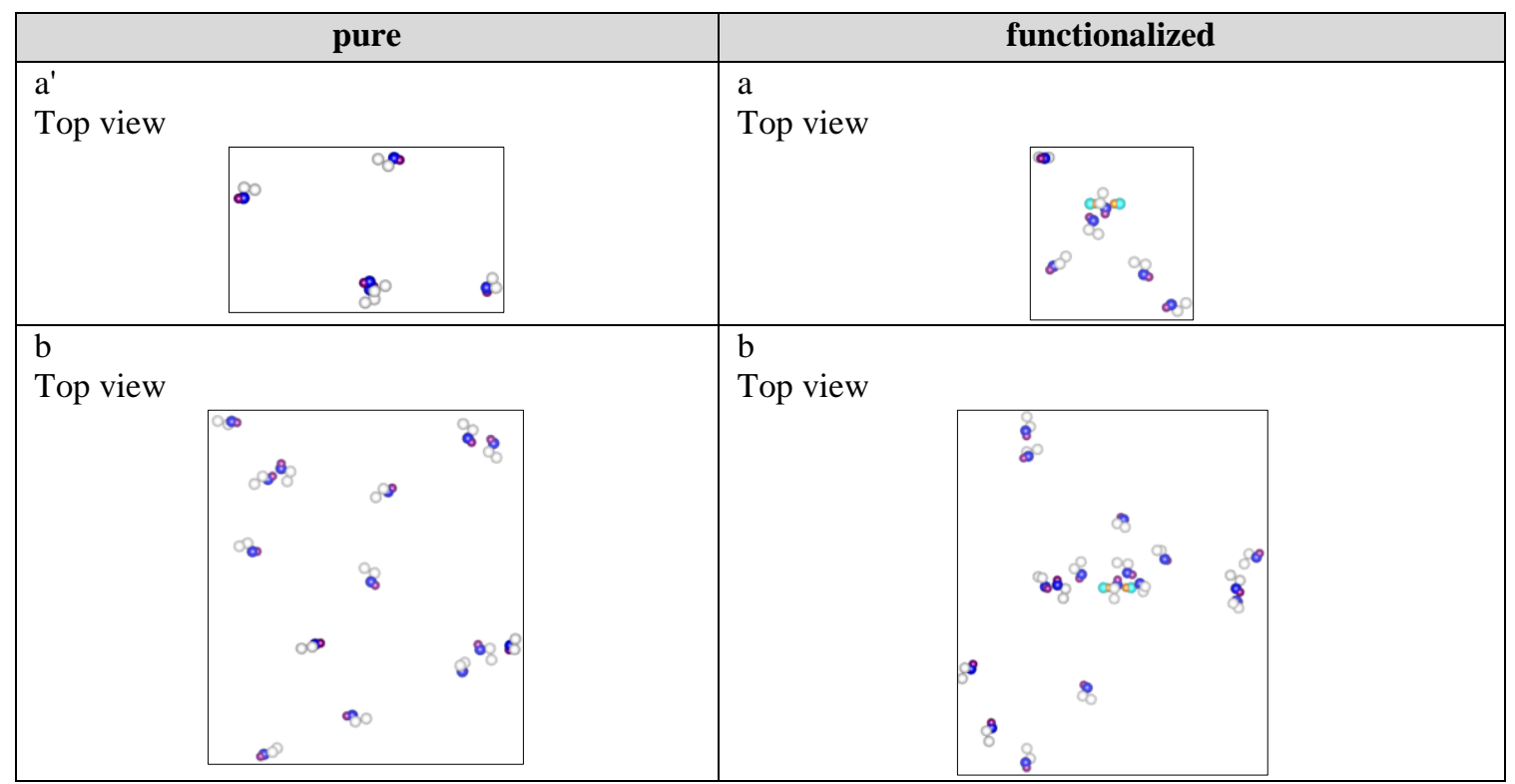




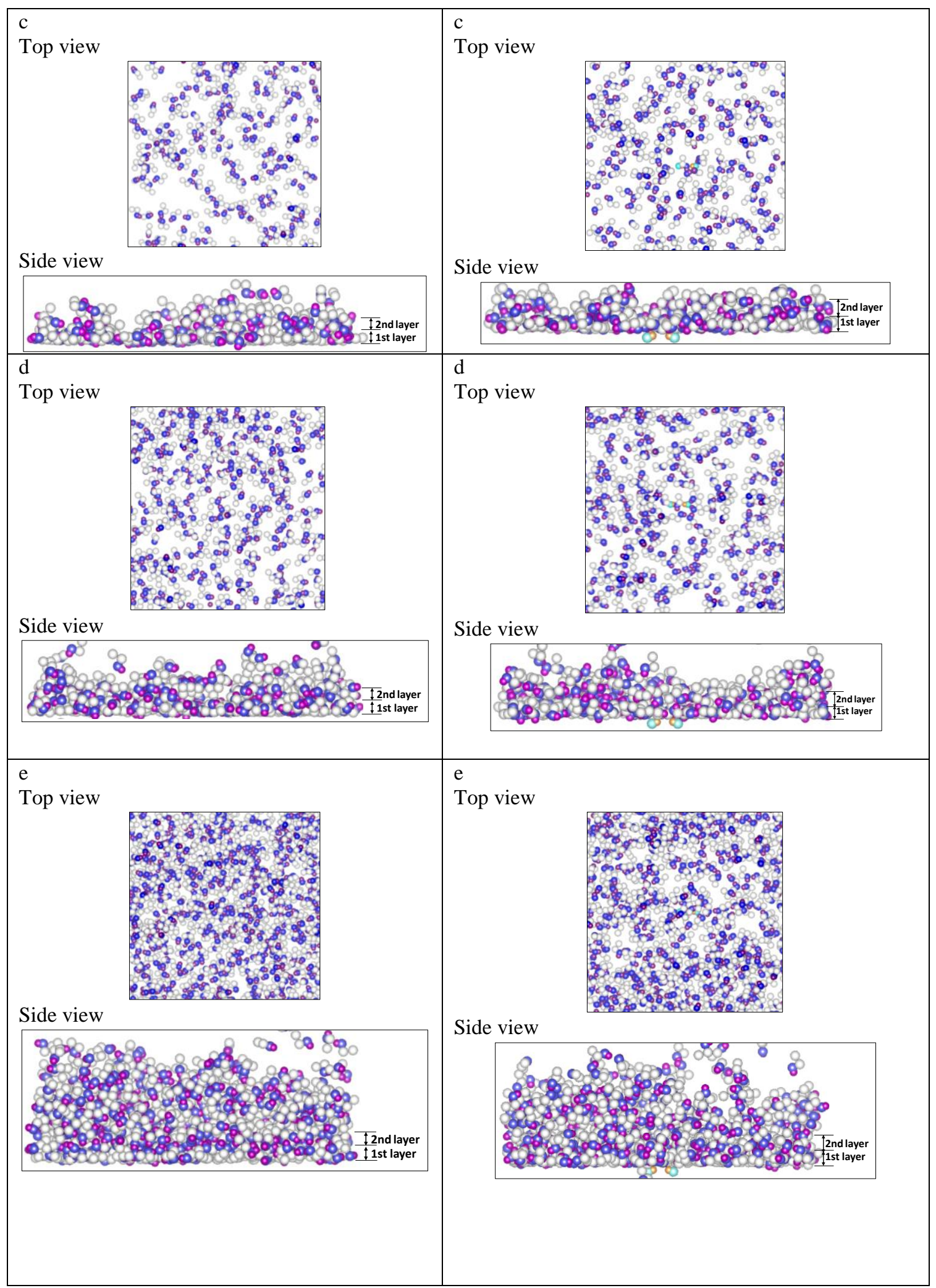




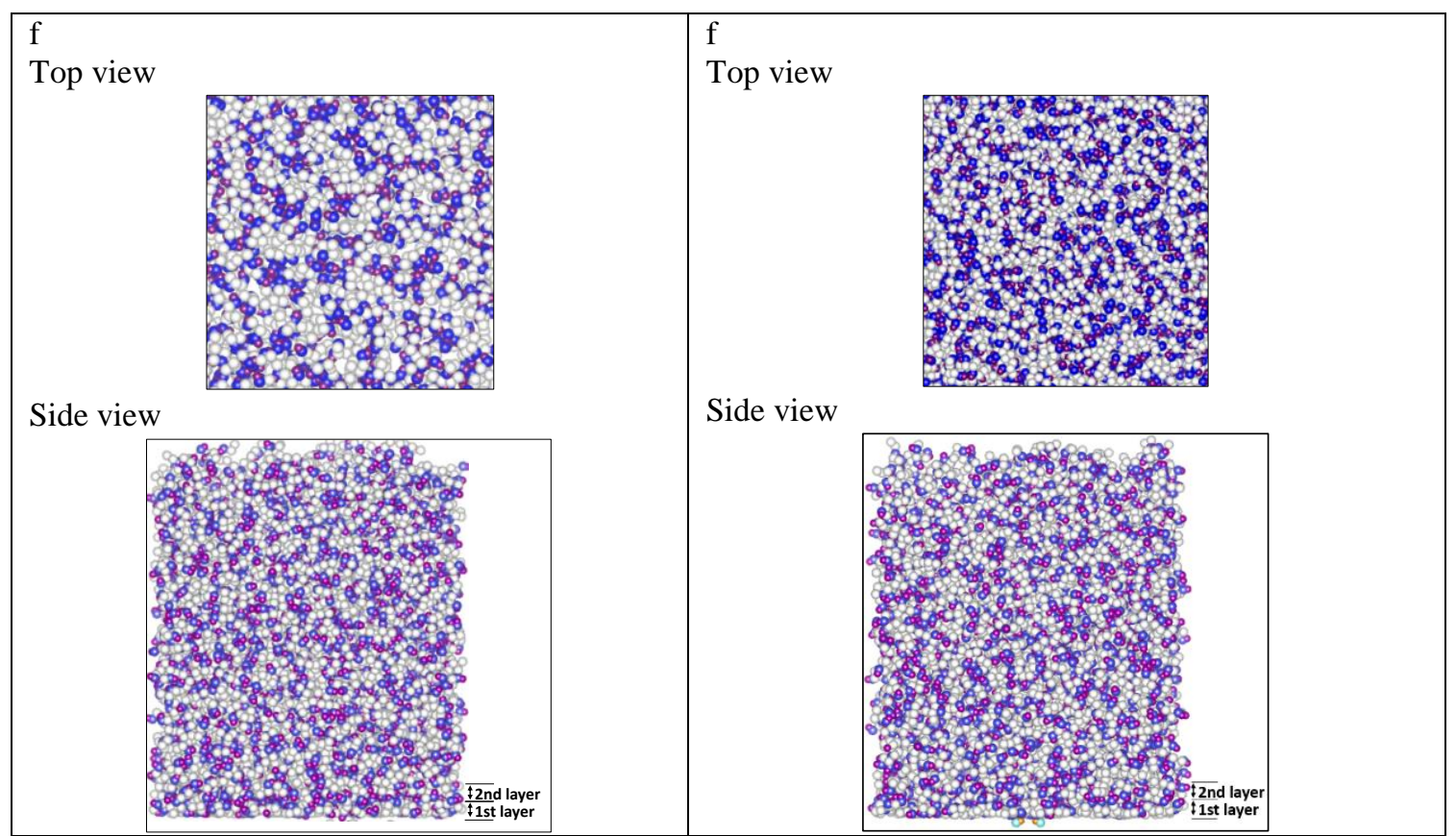

Figure S4. Snapshots of ethanol on pure and functionalized surfaces at $425 \mathrm{~K}$.

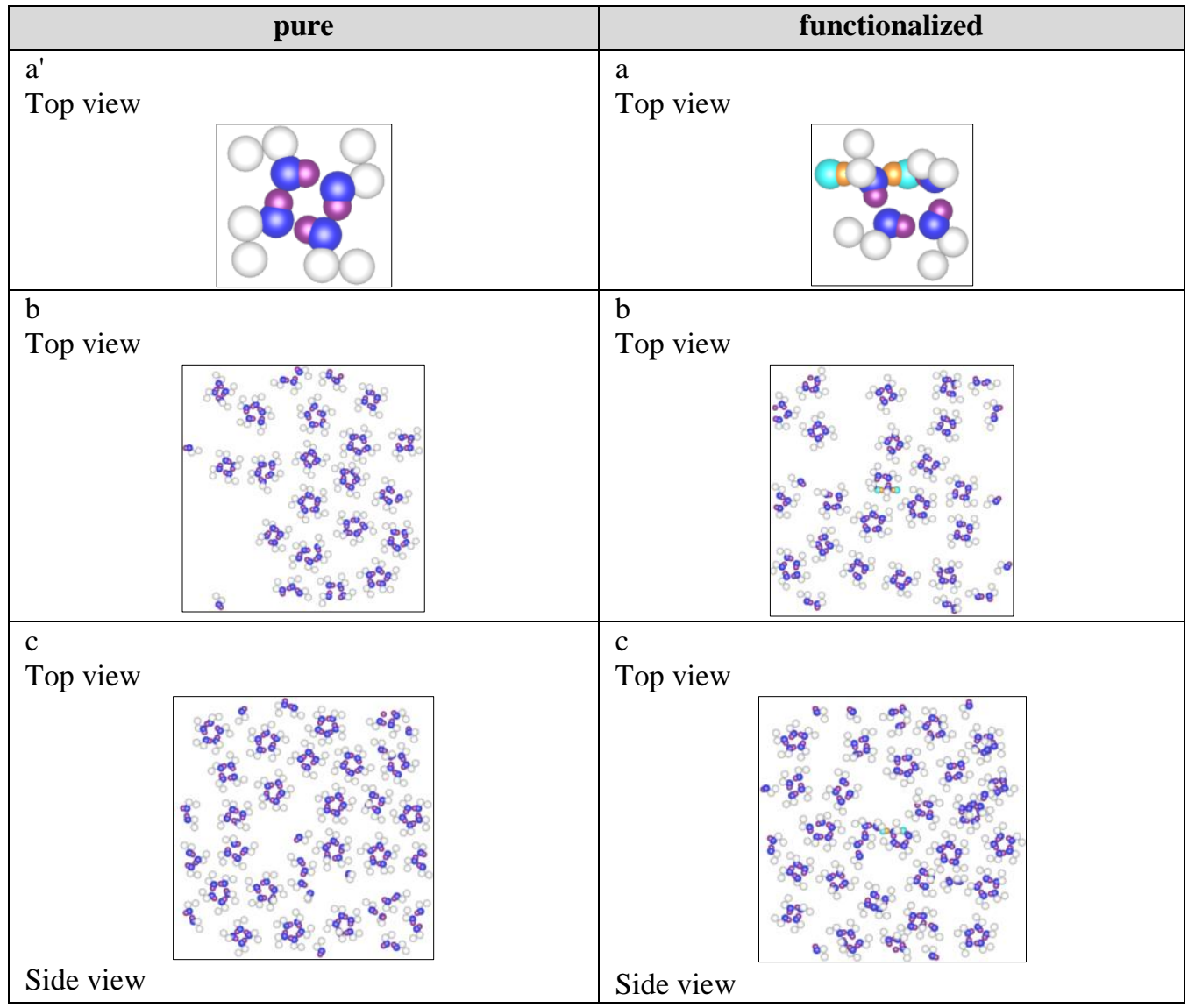




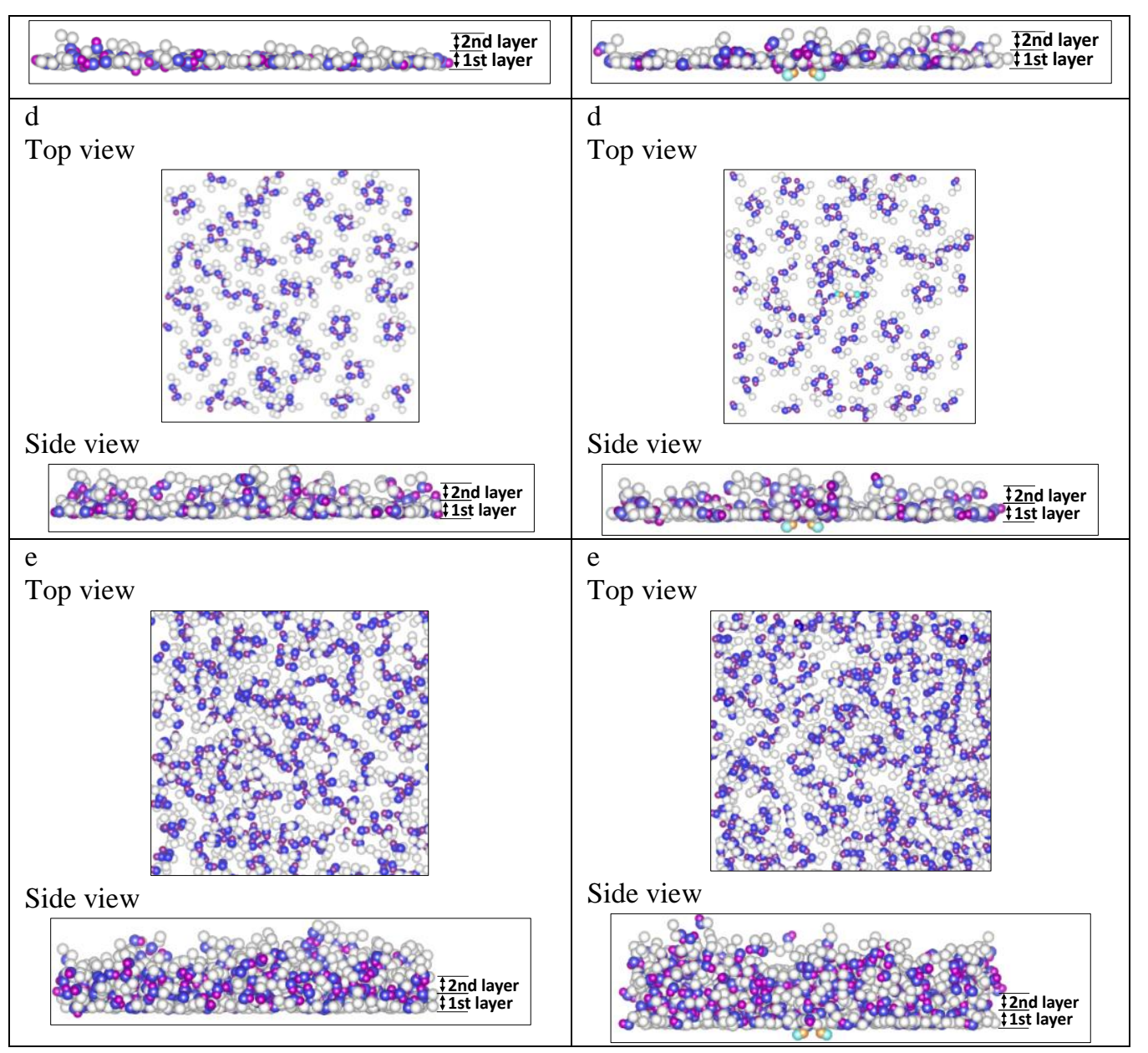

Figure S5. Snapshots of ethanol on pure and functionalized surfaces at 293K.

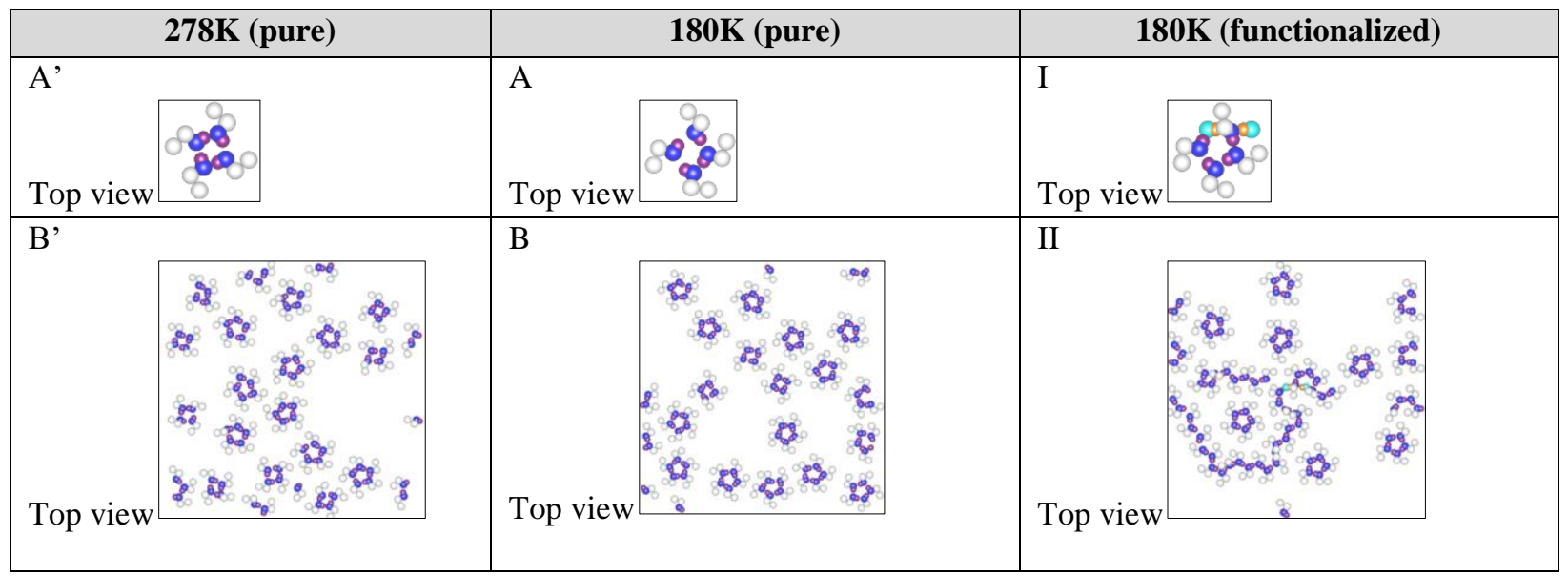




\begin{tabular}{|c|c|c|}
\hline 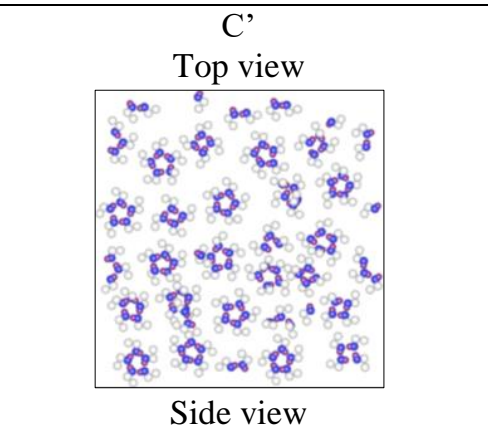 & 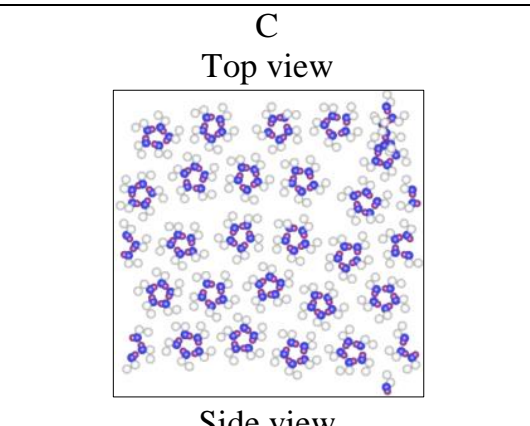 & 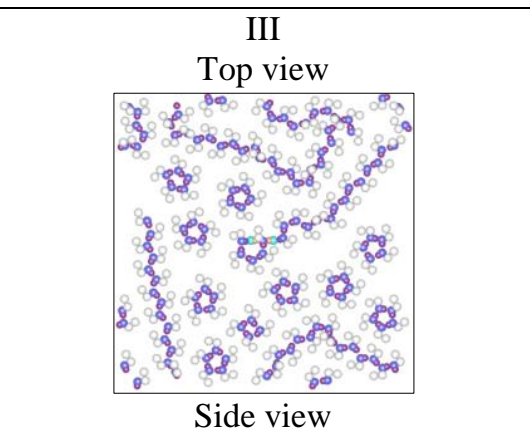 \\
\hline 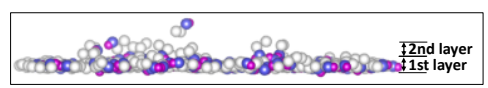 & 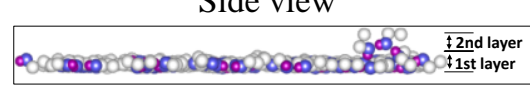 & 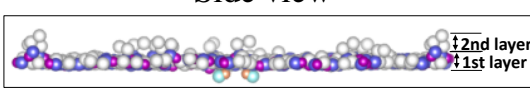 \\
\hline 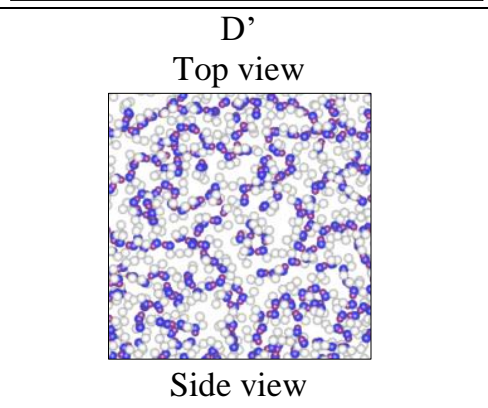 & 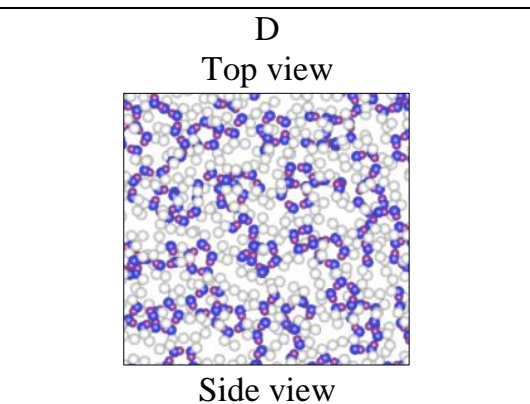 & 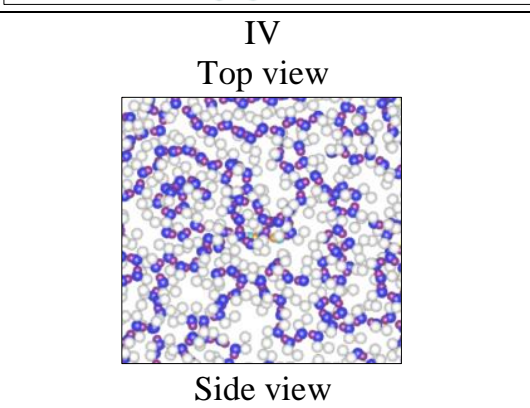 \\
\hline 3.9. & 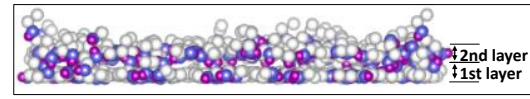 & 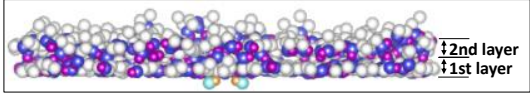 \\
\hline 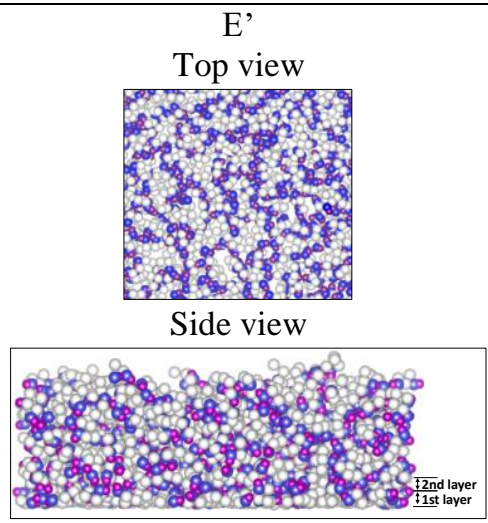 & & \\
\hline
\end{tabular}

Figure S6. Snapshots of ethanol on pure surface at $180 \mathrm{~K}$ and $278 \mathrm{~K}$ and on functionalized surface at $180 \mathrm{~K}$.

\begin{tabular}{|l|l|}
\hline \multicolumn{1}{|c|}{ Ethanol at 140K } & \multicolumn{1}{|c|}{ Methanol at 160K } \\
\hline $\begin{array}{l}\text { Point 1: Saturation of functional groups } \\
\text { Top view }\end{array}$ & $\begin{array}{l}\text { Point 7: Saturation of functional groups } \\
\text { Top view }\end{array}$ \\
\hline
\end{tabular}




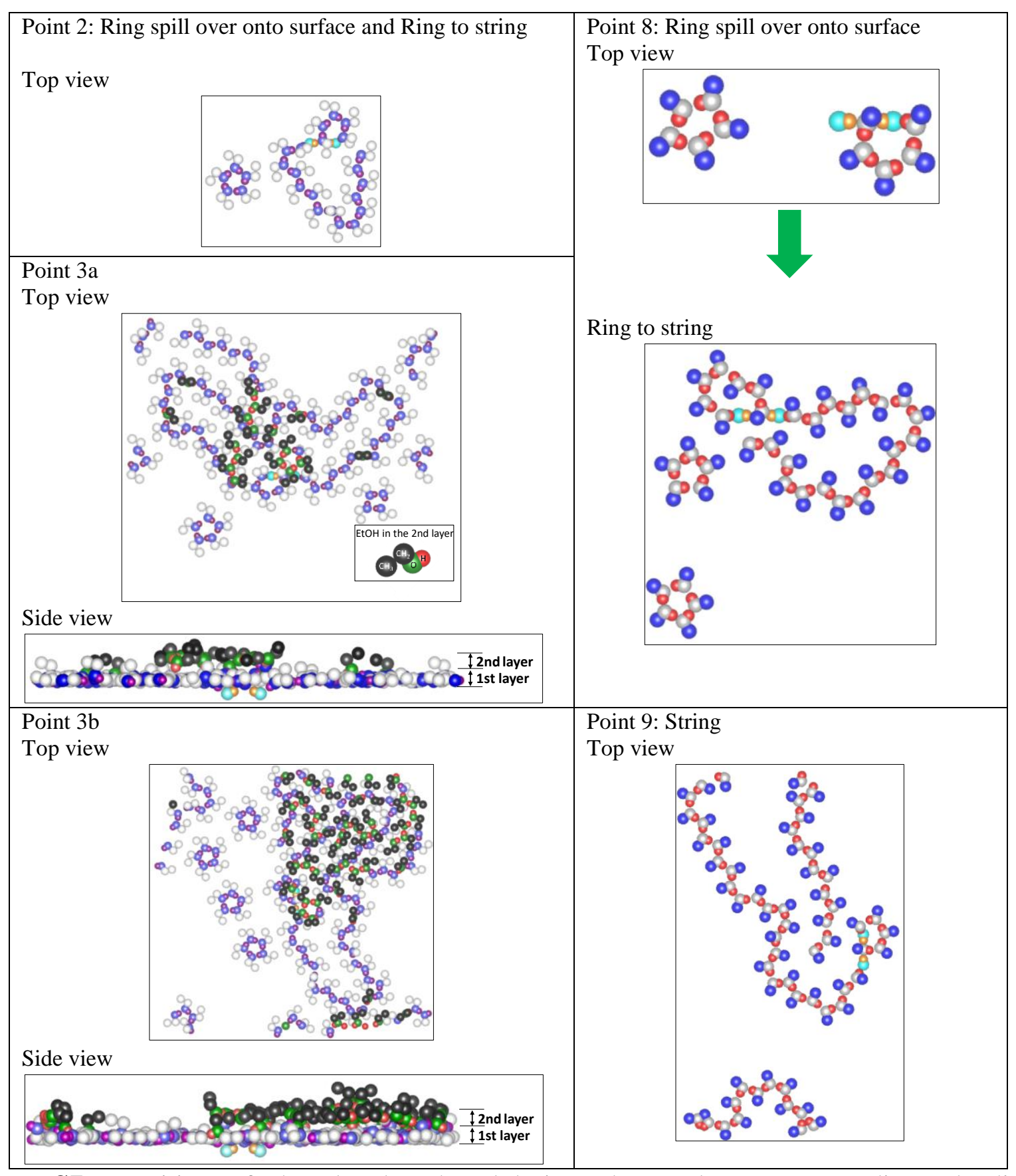

Figure S7. Transitions of ethanol and methanol during sub-monolayer corresponding to loadings in Figure12. 

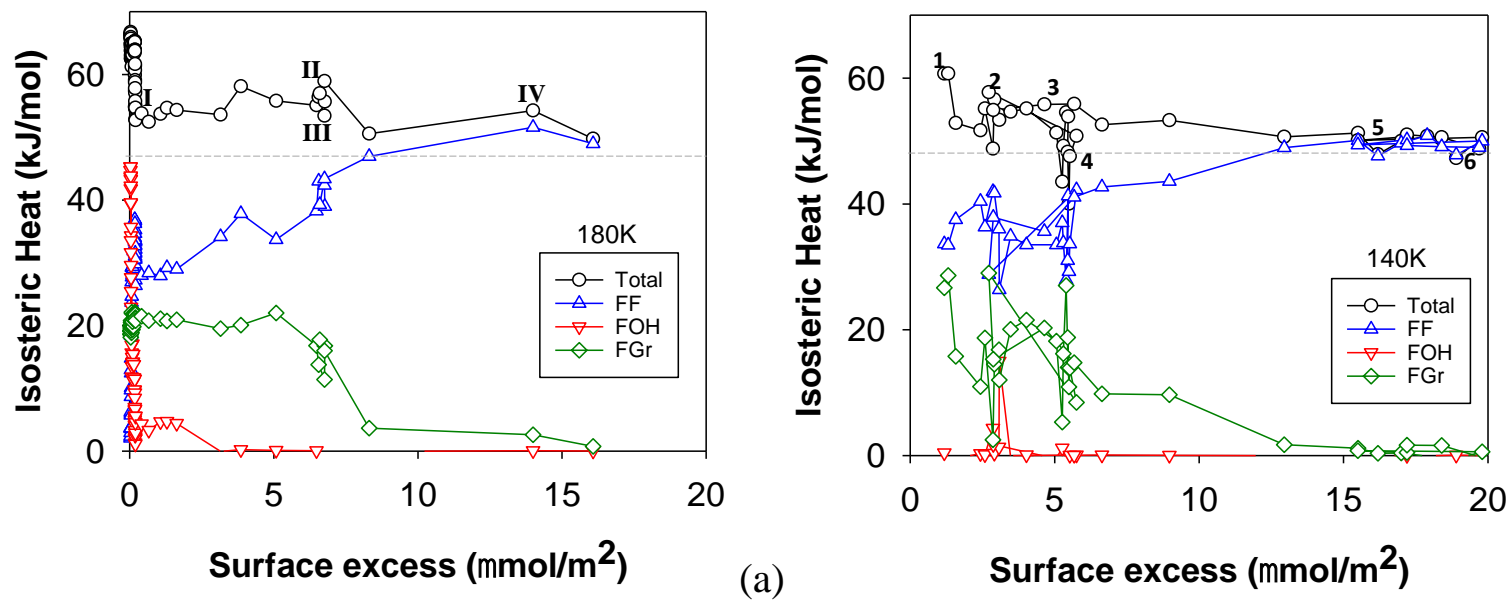

(b)

Figure S8. Heat contributions of ethanol on functionalized surface at (a) $180 \mathrm{~K}$ and (b) $140 \mathrm{~K}$.
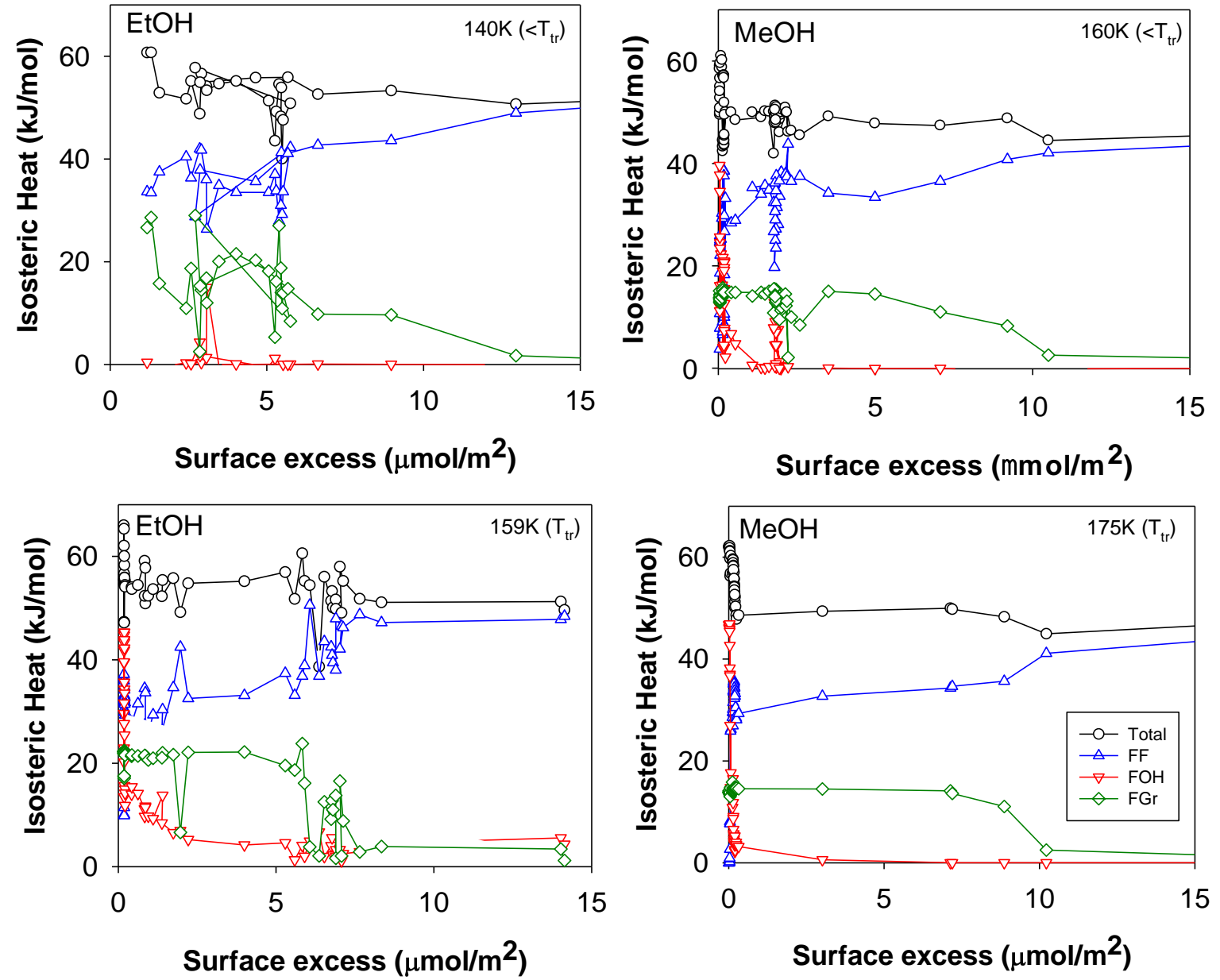

Figure S9. Heat contributions of ethanol and methanol below and at $\mathrm{T}_{\mathrm{tr}}$. 


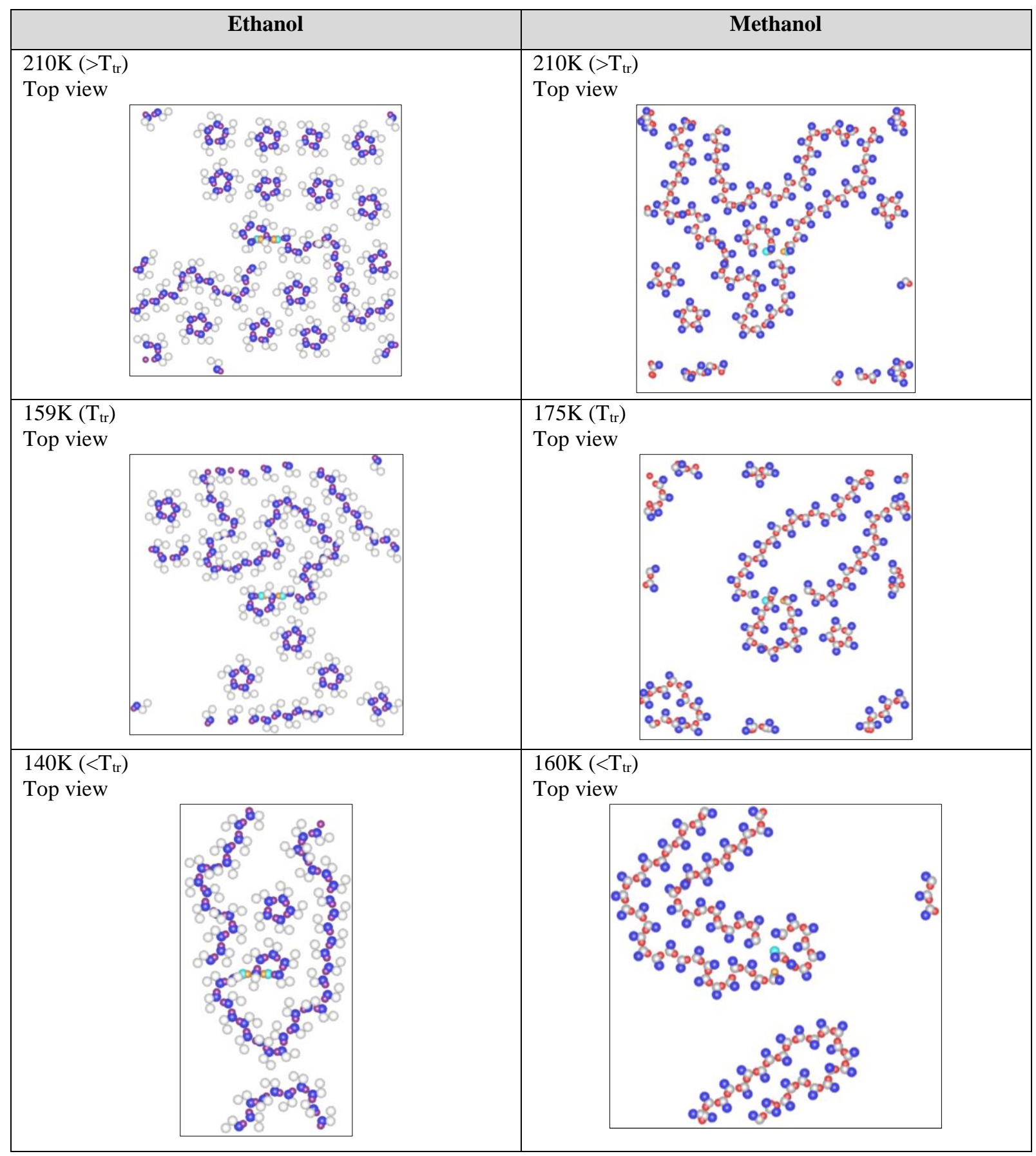

Figure S10. Top view snapshots of ethanol and methanol below, above, and at their $\mathrm{T}_{\text {tr }}$ at the same loading amount. 


\section{Reference}

(1) Chen, B.; Potoff, J.J.; Siepmann, J.I. Monte Carlo calculations for alcohols and their mixtures with alkanes. Transferable potentials for phase equilibria. 5. United-atom description of primary, secondary, and tertiary alcohols. J. Phys. Chem. B 2001, 105, 30933104. 